\title{
Association between Cardiovascular Risk Factors and Long-Term All-Cause Mortality in Thyroid Cancer Survivors: An Israeli Population-Based Study
}

Elena Izkhakov ( $\sim$ elenaiz@tlvmc.gov.il )

Tel Aviv Sourasky Medical Center https://orcid.org/0000-0002-4742-878X

Lital Keinan-Boker

University of Haifa School of Public Health

Micha Barchana

University of Haifa School of Public Health

Yacov Shacham

Tel Aviv Sourasky Medical Center

Iris Yaish

Tel Aviv Sourasky Medical Center

Narin N. Carmel Neiderman

Tel Aviv Sourasky Medical Center

Dan M. Fliss

Tel Aviv Sourasky Medical Center

Naftali Stern

Tel Aviv Sourasky Medical Center

Joseph Meyerovitch

Clalit Health Services

Research article

Keywords: thyroid cancer, mortality, cardiovascular risk factors

Posted Date: June 30th, 2020

DOI: https://doi.org/10.21203/rs.3.rs-39122/v1

License: (c) (i) This work is licensed under a Creative Commons Attribution 4.0 International License.

Read Full License

Version of Record: A version of this preprint was published on September 17th, 2020. See the published version at https://doi.org/10.1186/s12885-020-07401-3. 


\section{Abstract}

Background: The global incidence of thyroid cancer (TC) has risen considerably during the last three decades, while prognosis is generally favorable. We assessed the association between long-term allcause mortality and cardiovascular risk factors in TC survivors compared to the general population. Methods: Individuals diagnosed with TC during 2001-2014 (TC group) and age- and sex-matched individuals from the same Israeli healthcare system without thyroid disease or a cancer history (non-TC group) were compared. Cox regression hazard ratios (HRs) and $95 \%$ confidence intervals $(95 \% \mathrm{Cls})$ for allcause mortality were calculated by exposure status. Results: During a 15-year follow-up (median 8 years), 577 TC survivors out of 5,677 (10.2\%) TC patients and 1,235 individuals out of 23,962 (5.2\%) non-TC patients died. The TC survivors had an increased risk of all-cause mortality ( $\mathrm{HR}=1.89,95 \% \mathrm{Cl} 1.71-2.10)$, after adjusting for cardiovascular risk factors already present at follow-up initiation. This increased risk was most pronounced in the 55- to 64-year-old age group ( $\mathrm{HR}=1.49,95 \% \mathrm{Cl} 1.33-1.67)$. The TC survivors who died by study closure had more hypertension ( $14.6 \%$ vs. $10.3 \%, P=0.002)$, more dyslipidemia $(11.4 \%$ vs. $7.2 \%, \mathrm{P}<0.001)$, and more cardiovascular disease (33.6\% vs. $22.3 \%, \mathrm{P}=0.05)$ compared to those who died in the non-TC group. Conclusions: This large cohort study showed higher all-cause mortality with a higher prevalence of hypertension, dyslipidemia, and cardiovascular disease among TC survivors compared to matched non-TC individuals. Primary and secondary prevention of cardiovascular risk factors in TC survivors is mandatory.

\section{Introduction}

Thyroid cancer (TC) usually carries an excellent prognosis. Data from the United State Surveillance, Epidemiology, and End Results (SEER) program showed a case fatality rate from TC as being around 0.5 deaths per 100,000 TC survivors. ${ }^{1}$ However, a recent analysis of SEER data showed increasing rates of mortality and incidence of TC in the United States from 1974 to 2013, particularly for advanced-stage papillary TC. ${ }^{2}$ This is in contrast with an analysis of worldwide data through 2012 , which showed a declining mortality from TC in parallel with an increasing incidence. ${ }^{3}$ In Israel as well, nationwide trends show an increased incidence of TC and a modest increase in the 5-year relative survival during the last 3 decades. $^{4}$

A number of high-risk and pathological conditions have been reported among TC survivors compared to healthy controls, such as an increased prevalence of obesity and diabetes, ${ }^{5}$ aortic stiffness, ${ }^{6}$ and isolated left ventricular diastolic dysfunction. ${ }^{7}$ Data from the SEER program showed heart disease to be the cause of death for $34 \%$ of the non-cancer mortality among TC survivors. ${ }^{8}$ Data from our recently published Israeli population-based study showed a $26 \%$ increase in cardiovascular and cerebrovascular morbidity among thyroid cancer survivors compared to matched controls, who had neither thyroid disease nor any type of cancer. ${ }^{9}$ The risks of all-cause and cardiovascular mortality of differentiated TC (DTC) survivors in The Netherlands, independent of cardiovascular risk factors, were found to be increased by 4.4-fold 
and by 3.3-fold, respectively, compared to sex- and age-matched controls from the general population in the same region during a median follow-up of 8.5 years. $^{10}$

The increased morbidity ${ }^{5-7}$ and the increasing incidence of the disease worldwide ${ }^{3,11,12}$ lends special importance to understanding the elements that comprise the mortality risk of TC survivors. The aim of the current study, therefore, was to investigate the long-term all-cause mortality of a large cohort of Israeli TC survivors compared to individuals without either thyroid disease or a diagnosis of cancer who were members of the same healthcare system, while controlling for known cardiovascular risk factors at the beginning of the study and those diagnosed during a 15-year follow-up.

\section{Subjects And Methods Study Design}

This large historical cohort study (as previously described elsewhere) ${ }^{9}$ is based on the computerized data of the Clalit Health Services (CHS), the largest healthcare fund in Israel and a provider of healthcare to more than 4.3 million Israeli residents (52.3\% of the total Israeli population). The CHS database comprises demographic and medical data, including diagnoses, laboratory tests, drug prescriptions and purchases, and date (but not cause) of death.

\section{Study Population and Follow-up}

The TC survivors (TC group) included individuals diagnosed with TC between January 1, 2001 and December 31, 2014, who underwent thyroidectomy and received radioactive iodine treatment and levothyroxine therapy. The non-TC group was comprised of $\mathrm{CHS}$ members who had neither thyroid disease nor any type of cancer during the same time period. The non-TC group was matched to the TC group by sex and age ( \pm 2 years) at a ratio of $4: 1$. The follow-up of the TC survivors started on the date of TC diagnosis, and the follow-up of the matched non-TC individuals started in the same year of diagnosis as the TC survivors to whom they were matched. The follow-up of both groups ended on June 30, 2016 or on the date of death, whichever occurred earlier.

\section{Methods}

The Medical Ethics Committee of the CHS provided approval to conduct this study. Signed informed consent from the participants was waived since the study was based on existing databases. The study inclusion criteria were membership in the CHS throughout the entire study period (January 1, 2001 to June 30,2016 ) and age $\geq 18$ years. The exclusion criteria were any other primary cancer prior to study entry, with the exception of squamous or basal cell carcinoma of the skin, and advanced renal failure (creatinine $>1.5 \mathrm{mg} / \mathrm{dL}$ ), the latter because of its impact on the clinical decisions regarding the application of radioactive iodine treatment.

\section{Study Variables}


The following data were collected for the TC and non-TC groups: demographic characteristics, smoking status, anthropometric characteristics, mean blood pressure, pulse rate, and laboratory tests that included levels of glucose and creatinine, lipid profile, and thyroid function tests at a date closest to study entry, and any diagnosed pathological conditions at study entry and at the end of the follow-up.

Diabetes mellitus was defined as having at least one of the following upon study entry: a diagnosis of diabetes mellitus recorded in the CHS database, 2 plasma glucose measurements $>125 \mathrm{mg} / \mathrm{dL}$, a random plasma glucose measurement $>199 \mathrm{mg} / \mathrm{dL}$, or a record of hypoglycemic medications. Hypertension was defined as having at least one of the following upon study entry: a diagnosis of hypertension recorded in the CHS registry, 3 or more measurements of systolic blood pressure $>140 \mathrm{~mm} \mathrm{Hg}$ or diastolic blood pressure $>90 \mathrm{~mm} \mathrm{Hg}$, or a record of medications for hypertension. Dyslipidemia was defined as having at least one of the following upon study entry: a diagnosis of hyperlipidemia recorded in the CHS registry, at least 2 plasma low density lipoprotein ( $L D L)$ cholesterol measurements $>160 \mathrm{mg} / \mathrm{dL}$, a triglyceride level > $150 \mathrm{mg} / \mathrm{dL}$, or a high-density lipoprotein cholesterol level $<40 \mathrm{mg} / \mathrm{dL}$ for males or $<50 \mathrm{mg} / \mathrm{dL}$ for females, or a record of hypolipidemic medications. Cardiovascular disease was defined by the International Statistical Classification of Diseases and Related Health Problems (ICD) code as having at least one of the following diagnoses recorded in the CHS database upon study entry: ischemic heart disease, acute myocardial infarction, percutaneous transluminal coronary angioplasty, or coronary artery bypass graft. Cerebrovascular disease was defined by ICD code as having at least one of the following diagnoses recorded in the CHS database code upon study entry: transient ischemic attack, cerebrovascular accident, carotid artery stenosis/occlusion, or carotid endarterectomy. The prevalence of diabetes mellitus, hypertension, dyslipidemia, and cardiovascular and cerebrovascular diseases at the end of follow-up was assessed according to the same definitions as those for the beginning of follow-up.

\section{Statistical Analyses}

Baseline patient characteristics are presented as means and standard deviations for continuous variables, and as frequencies and percentages for categorical variables. Independent t-tests and Chisquare tests were used to compare between the study groups for continuous and categorical variables, respectively. Unadjusted and adjusted Cox proportional hazard models were performed to evaluate the hazard ratios (HRs) and 95\% confidence intervals (95\% Cls) for death. Kaplan-Meier-based adjusted survival curves for mortality are provided. All-cause mortality risk was compared between the TC and nonTC groups by gender and age ( $\leq 44,45-54,55-64,65-74$, and $\geq 75$ years) at study entry. Unadjusted and adjusted Cox proportional hazard models were performed to evaluate the HRs and $95 \% \mathrm{Cls}$ for longterm mortality by a minimum latency period of 2 years. Data were analyzed with SPSS software version 23.0. (SPSS Inc. Headquarters, $233 \mathrm{~S}$. Wacker Drive, 11th floor Chicago, Illinois 60606, USA). A 2-sided $P$ value less than 0.05 was considered statistically significant.

\section{Results}

\section{Baseline Characteristics of the TC and Non-TC Groups}


The TC group was comprised of 5,677 TC survivors (mean age $50 \pm 16$ years) of whom $21.4 \%$ were males. The non-TC group was comprised of 23,962 members of CHS (mean age $47 \pm 15$ years) of whom $20.5 \%$ were males. Although the study sample was matched for age and sex, exclusion of individuals with renal failure slightly changed the distributions (Table 1). ${ }^{9}$ At baseline, the anthropometric characteristics, mean blood pressure, and pulse rate were similar between the study and control groups (Table 1). ${ }^{9} \mathrm{~A}$ higher proportion of individuals in the TC group had hypertension compared to the non-TC group $(24.7 \%$ vs. $19.3 \%$, respectively, $P<0.001)$ and dyslipidemia $(32.9 \%$ vs. $28.5 \%, P<0.001)$, and a lower proportion had cardiovascular and cerebrovascular diseases ( $1.4 \%$ vs. $4.9 \%$ and $0.5 \%$ vs. $1.7 \%, P<$ 0.001 for both) (Table 2). ${ }^{9}$

Table 1

Baseline characteristics of the thyroid cancer survivors $(n=5,677)$ and the non-thyroid cancer individuals $(n=23,962)$.

\begin{tabular}{|c|c|c|}
\hline Characteristic & $\begin{array}{l}\text { Cancer group } \\
(n=5,677)\end{array}$ & $\begin{array}{l}\text { Non-cancer group } \\
(n=23,962)\end{array}$ \\
\hline Male sex, $n(\%)$ & $1,216(21.4)$ & $4,912(20.5)$ \\
\hline Age, years, mean $\pm S D$ & $50 \pm 16$ & $47 \pm 15$ \\
\hline Median (range) & $49(18-108)$ & $46(17-100)$ \\
\hline Smoking & $371(6.5)$ & $1249(5.2)$ \\
\hline Past, $n(\%)$ & $947(16.7)$ & $6080(25.4)$ \\
\hline \multicolumn{3}{|l|}{ Current, $n(\%)$} \\
\hline Weight, kg, mean \pm SD & $78 \pm 21$ & $76 \pm 21$ \\
\hline Height, $\mathrm{cm}$, mean \pm SD & $164 \pm 8.7$ & $163 \pm 8.6$ \\
\hline $\mathrm{BMI}, \mathrm{kg} / \mathrm{m}^{2}$, mean $\pm \mathrm{SD}$ & $28.5 \pm 6.49$ & $28.0 \pm 6.8$ \\
\hline$<18.5, n(\%)$ & $38(1.4)$ & $256(2.0)$ \\
\hline $18.5-24.99, n(\%)$ & $820(30.9)$ & $4527(34.7)$ \\
\hline $25-29.99, n(\%)$ & $893(33.7)$ & $4221(32.4)$ \\
\hline$\geq 30, n(\%)$ & $900(33.9)$ & $4031(30.9)$ \\
\hline $\mathrm{SBP}, \mathrm{mm} \mathrm{Hg}$, mean $\pm \mathrm{SD}$ & $123 \pm 15$ & $122 \pm 16$ \\
\hline $\mathrm{DBP}, \mathrm{mm} \mathrm{Hg}$, mean $\pm \mathrm{SD}$ & $75.4 \pm 9.0$ & $74.6 \pm 10.6$ \\
\hline Pulse, beat $/$ min, mean \pm SD & $76 \pm 10.2$ & $76 \pm 10.4$ \\
\hline
\end{tabular}


Table 2

Baseline morbidity of the thyroid cancer survivors $(n=5,677)$ and non-thyroid cancer individuals $(n=$ $23,962)$

\begin{tabular}{|c|c|c|c|}
\hline Variable & $\begin{array}{l}\text { Cancer } \\
\text { group } \\
(n=5,677)\end{array}$ & $\begin{array}{l}\text { Non-cancer } \\
\text { group } \\
(n=23,962)\end{array}$ & $P$ \\
\hline Hypertension ${ }^{\mathrm{a}}, \mathrm{n}(\%)$ & $1,405(24.7)$ & $4,629(19.3)$ & $\begin{array}{l}<.001 \\
0.00\end{array}$ \\
\hline Diabetes mellitus ${ }^{\mathrm{b}}, \mathrm{n}(\%)$ & $707(12.5)$ & $2,681(11.2)$ & 0.007 \\
\hline Dyslipidemia ${ }^{\mathrm{c}}, \mathrm{n}(\%)$ & $1,865(32.9)$ & $6,822(28.5)$ & $<.001$ \\
\hline $\mathrm{AF}, n(\%)$ & $170(0.3)$ & $117(0.5)$ & $\hat{0.001}$ \\
\hline Rheumatic heart disease, $n(\%)$ & $8(0.1)$ & $16(0.1)$ & 0.077 \\
\hline Fatty liver, $n(\%)$ & $101(1.8)$ & $285(1.2)$ & $\dot{0} 001$ \\
\hline Cerebrovascular disease $^{*} 1, n(\%)$ & $53(0.9)$ & $624(2.6)$ & $\hat{0} .001$ \\
\hline Cardiovascular disease ${ }^{\star} 2, n(\%)$ & $119(2.1)$ & $1,330(5.6)$ & $<.001$ \\
\hline $\begin{array}{l}\text { Cerebrovascular \& cardiovascular diseases }{ }^{*} 1 \&{ }^{*} 2, n \\
(\%)\end{array}$ & $154(2.7)$ & $1.631(6.8)$ & $\dot{0} 001$ \\
\hline \multicolumn{4}{|c|}{$\begin{array}{l}\text { aPhysician diagnosis of hypertension or at least three measurements of systolic blood pressure }> \\
140 \mathrm{~mm} \mathrm{Hg} \text {, or of diastolic blood pressure }>90 \mathrm{~mm} \text { Hg, or hypertension medications; }{ }^{b} \text { Physician } \\
\text { diagnosis of diabetes mellitus, or twice blood fasting glucose } \geq 126 \mathrm{mg} / \mathrm{dL} \text {, or random blood glucose } \\
\geq 200 \mathrm{mg} / \mathrm{dL} \text {, or hypoglycemic medications; }{ }^{C} \text { Physician diagnosis of hyperlipidemia, or at least two } \\
\text { measurements of } \mathrm{LDL}>160 \mathrm{mg} / \mathrm{dL} \text {, or } \mathrm{TG}>150 \mathrm{mg} / \mathrm{dL} \text {, or } \mathrm{HDL}<40 \mathrm{mg} / \mathrm{dL} \text { for males, or } \mathrm{HDL}< \\
50 \mathrm{mg} / \mathrm{dL} \text { for females, or hypolipidemic medications. AF, Atrial fibrillation; }{ }^{*} 1 \text {, Transient ischemic } \\
\text { attack, cerebral vascular attack, carotid artery stenosis and occlusion, carotid endarterectomy; }{ }^{*} 2 \text {, } \\
\text { Ischemic heart disease, acute myocardial infarction, percutaneous transluminal coronary angioplasty, } \\
\text { coronary artery bypass graft. }\end{array}$} \\
\hline Bold indicates significant. & & & \\
\hline
\end{tabular}

\section{Mortality in the TC and Non-TC Groups}

During the study period, a total of 1,812 participants died, of whom $577(10.2 \%)$ were in the TC group and $1,235(5.2 \%)$ in the non-TC group. The mean survival for those who died was $7.6 \pm 4.2$ and $8.0 \pm 4.1$ years, respectively. All-cause mortality for the entire cohort was associated with being older (HR $1.11 ; 95 \% \mathrm{Cl}$ : 1.10-1.11), having a diagnosis of hypertension (HR 1.15; 95\% Cl: 1.02-1.29) or diabetes mellitus (HR $1.68 ; 95 \% \mathrm{Cl}: 1.52-1.86)$, or having a previous cerebrovascular disease (HR 1.39; 95\% Cl: $1.16-1.68)$ or a 
cardiovascular disease (HR 1.31; 95\% Cl: 1.09-1.56), and current smoking (HR 1.32; 95\% Cl: 1.17-1.50). Female gender and a diagnosis of dyslipidemia were associated with a lower risk for mortality (HR 0.70; 95\%Cl: $0.63-0.78$ and HR 0.85; 95\%Cl: 0.76-0.94, respectively). The mean baseline glucose and LDL levels were higher among those who died than among those who survived $(120 \pm 52$ vs. $90 \pm 29, P<0.001$ and $199 \pm 43$ vs. $193 \pm 38, P<0.001$, respectively). In the univariate analysis, the HR for mortality in the Tc group compared to the non-Tc group was 2.03 (95\% Cl: 1.84-2.24). In a model adjusted for age and sex, the HR for mortality was $1.78(95 \% \mathrm{Cl}: 1.61-1.96)$ for the TC group compared to the non-TC group. The HR for mortality in the TC survivors compared to the controls was even stronger, i.e., HR 1.89 (95\% Cl: 1.71-2.10), after further adjustment for age, sex, prevalence of cerebrovascular and cardiovascular disease, hypertension, diabetes mellitus, dyslipidemia, and current smoking at the time of study onset. The Kaplan-Meier survival curve of the TC group was steeper than that of the non-TC group (Fig. 1). After stratifying by sex and adjusting for age and for the prevalence of cerebrovascular and cardiovascular disease, hypertension, diabetes mellitus, dyslipidemia and current smoking at study onset, the HR for mortality was higher for male TC survivors (HR 2.53, 95\%Cl: $2.10-3.03$ ) than for female TC survivors (HR 1.79, 95\%Cl: 1.58-2.03).

The adjusted HRs for mortality in the TC group compared to the non-TC group were significantly elevated in all age groups, with the 55- to 64-year age group showing the highest hazard $(\mathrm{HR}=1.49,95 \% \mathrm{Cl}$ : $1.33-$ 1.67) (Table 3). Stratification by follow-up period in the TC group showed the following time distribution of mortality events: $7.1 \%$ in years $0-2$ after TC diagnosis, $25.8 \%$ in years $2-5,36.2 \%$ in years $5-10$, and $30.9 \%$ in $>10$ years. 
Table 3

Cox proportional hazard ratios of mortality in the thyroid cancer survivors $(n=5,677)$ and the non-thyroid cancer individuals $(n=23,962)$ age, crude hazard ratios adjusted for covariates ${ }^{a}$

\begin{tabular}{|c|c|c|c|c|}
\hline Age & $\begin{array}{l}\text { Crude HR for } \\
\text { death in the } \\
\text { cancer vs. } \\
\text { non-cancer groups } \\
(95 \% \mathrm{Cl})\end{array}$ & $P$ value & $\begin{array}{l}\text { Adjusted HR for death in the } \\
\text { cancer vs. } \\
\text { non-cancer groups } \\
(95 \% \mathrm{Cl})\end{array}$ & $P$ value \\
\hline$\geq 44$ & $1.49(1.25-1.77)$ & $<0.001$ & $1.33(1.06-1.67)$ & $<0.05$ \\
\hline $45-54$ & $1.34(0.96-1.89)$ & 0.088 & $1.25(1.06-1.48)$ & $<0.05$ \\
\hline $55-64$ & $2.02(1.61-2.54)$ & $<0.001$ & $1.49(1.33-1.67)$ & $<0.001$ \\
\hline $65-74$ & $1.62(1.35-1.95)$ & $<0.001$ & $1.33(1.21-1.46)$ & $<0.001$ \\
\hline $75+$ & $1.49(1.25-1.77)$ & $<0.001$ & $1.35(1.24-1.47)$ & $<0.001$ \\
\hline \multicolumn{5}{|c|}{ HR, Hazard ratio; Cl, Confidence interval. } \\
\hline \multicolumn{5}{|c|}{$\begin{array}{l}\text { aAdjusted for sex, cerebrovascular and cardiovascular disease, hypertension, diabetes mellitus, } \\
\text { dyslipidemia, and current smoking. }\end{array}$} \\
\hline \multicolumn{5}{|c|}{ Bold indicates significant. } \\
\hline
\end{tabular}

The mortality events that occurred during the first 2 years of follow-up were excluded in order to allow a minimal latency period and to assess long-term mortality. The subsequent HR for mortality in the TC group adjusted for prevalent cardiovascular risk factors (age, sex, hypertension, diabetes mellitus, dyslipidemia, and current smoking) and for prevalent atherosclerotic cardiovascular and cerebrovascular disease at follow-up onset remained significantly increased (HR 1.59, 95\% Cl: 1.40-1.80).

\section{Characteristics of the Individuals Who Died}

Compared to the individuals in the non-TC group who died, the TC survivors who died had a higher prevalence of hypertension ( $14.6 \%$ vs. $10.3 \%$, respectively, $P=0.002)$, dyslipidemia $(11.4 \%$ vs. $7.2 \%, P<$ $0.001)$, and cardiovascular disease (33.6\% vs. $22.3 \%, P<0.001)$ at the end of the 15 -year follow-up period. During the study period, second primary tumors among the TC survivors who died were not more common than primary tumors among the individuals in the non-TC group who died. Stratification of the TC patient group by selected cardiovascular risk factors (hypertension, dyslipidemia, diabetes mellitus, and cardiovascular and cerebrovascular disease) at the end of the follow-up revealed a direct association between the number of those risk factors and mortality risk (Table 4). 
Table 4

Cox proportional hazard ratios of mortality in the thyroid cancer survivors $(n=$ 5,677 ) by number of cardiovascular risk factors (hypertension, dyslipidemia, diabetes mellitus, cardiovascular or cerebrovascular disease) at the end of the follow-up period, crude and adjusted for covariates ${ }^{a}$

\begin{tabular}{|lllll|}
\hline Number of CV RF & $\begin{array}{l}\text { Crude HR } \\
(95 \% \mathrm{Cl})\end{array}$ & $P$ value & $\begin{array}{l}\text { Adjusted HR } \\
(95 \% \mathrm{Cl})\end{array}$ & $P$ value \\
\hline 1 & $1.27(0.94-1.70)$ & 0.12 & $0.97(0.81-1.16)$ & 0.72 \\
\hline 2 & $2.89(2.19-3.81)$ & $<0.001$ & $1.23(1.03-1.47)$ & 0.02 \\
\hline 3 & $4.86(3.65-6.47)$ & $<0.001$ & $1.66(1.38-1.99)$ & $<0.001$ \\
\hline 4 & $6.73(4.71-9.63)$ & $<0.001$ & $2.59(2.11-3.19)$ & $<0.001$ \\
\hline CV RF, Cardiovascular risk factors; HR, Hazard ratio; Cl, Confidence interval. \\
\hline \multicolumn{4}{|l}{ aAdjusted for age and sex. } \\
\hline
\end{tabular}

\section{Discussion}

\section{Overall all-cause mortality risk}

This large Israeli population-based historical cohort study demonstrated a higher all-cause mortality rate among TC survivors than among individuals without any thyroid disease or any type of cancer from the same population, matched by sex and age. The difference remained statistically significant after adjusting for age, sex, baseline cardiovascular risk factors, and cardiovascular and cerebrovascular diseases at study onset. The novel findings of this study are the association between cardiovascular risk factors at the end of follow-up and the higher mortality among Israeli TC survivors compared to non-TC individuals. In contrast, there was no association between mortality and the presence of a second primary malignancy in the former group and the presence of a primary malignancy in the latter group at the end of follow-up.

The majority of the TC survivors in the current cohort were female (79\%). Stratification by sex showed that the mortality HR for male TC survivors was higher than that of females. Similarly, analysis of the SEER data revealed a higher mortality rate among male TC survivors than among females. ${ }^{2}$ Moreover, during the last three decades, age-adjusted mortality attributed to TC was reported to remain stable among Israeli men and to decrease among Israeli women. ${ }^{4}$

Surprisingly, female gender and a diagnosis of dyslipidemia at the beginning of the follow-up for the entire cohort were associated with a lower risk for mortality. This finding may be explained at least in part by statin treatment. 


\section{Mortality Risk by Age}

There was a significant and pronounced age-related increased mortality risk for TC survivors compared to the non-TC group, particularly from age 55 years onwards. Our findings concur with a recent study that found 55 years to be a valid cutoff age for risk assessment in TC survivors. ${ }^{13}$ Another recent publication concluded that the increasing age risk should be considered along a continuum. ${ }^{14}$ The SEER study also reported that the 5 -year and 10-year probability of death increased with age among TC survivors. ${ }^{8}$ The lower relative mortality risk among younger TC survivors is supported by the results of a German study that disclosed no reduced life expectancy among DTC survivors who were under 45 years of age at DTC diagnosis and with tumor-node-metastasis (TNM) stages I, II, or III compared to the general population. ${ }^{15}$

\section{Factors Contributing to Increased Mortality among TC Survivors}

The interpretation of our results should take into account the various factors that may contribute to increased mortality in TC survivors. First, despite the excellent prognosis and the low and decreasing fatality rates, the small proportion of TC survivors who die of their disease naturally increases the general mortality rate in TC survivors, particularly in the long term during which recurrence is a factor. In a Dutch study, ${ }^{10}$ progression or recurrence of TC was the cause of mortality for $39 \%$ of TC survivors who died during a mean follow-up of 8.5 years. An increased risk of second primary cancers, compared to the general population, may also increase overall mortality. Such risk has been documented in Israel ${ }^{16}$ and elsewhere. ${ }^{17}$ Although a second primary cancer also worsens the prognosis of TC survivors, ${ }^{18}$ a second primary cancer was not more common among the TC survivors who died than a de novo primary cancer among the individuals who died in the non-TC group in the current study. However, analyses of the current findings revealed a direct association between the number of cardiovascular risk factors and mortality risk among the TC patients.

Increased mortality due to non-cancer causes must also be considered in relation to TC. SEER data showed that the risk of dying from a cause other than the primary disease in TC survivors is nearly 2-fold than that of dying from TC. ${ }^{8}$ In that study, the 10-year probabilities of death from TC, from other cancers, and from non-cancer causes were $3.0 \%, 2.0 \%$ and $3.9 \%$, respectively. In the current study, increased mortality persisted after controlling for baseline cardiovascular risk factors and morbidity, in addition to age and sex. At the time of TC diagnosis, the anthropometric and clinical characteristics of the TC survivors were very similar to those of the non-cancer individuals, with the exception of hypertension, which was slightly more prevalent among the TC survivors. Similarly, a Dutch population-based study reported a higher than expected prevalence of hypertension among TC survivors. ${ }^{19}$ In the current study, the prevalence of diabetes mellitus at baseline was similar between the TC group and the non-TC group. This concurs with a recently published Israeli study that was based on a nationwide cohort and which found no association between diabetes mellitus and TC. ${ }^{20}$ Nevertheless, diabetes mellitus may still affect TC prognosis. For example, TC survivors with type 2 diabetes mellitus and DTC were found to be more 
likely to have an advanced TNM stage at the time of diagnosis as well as increased disease-specific mortality. ${ }^{21}$ The prevalence of hypertension, dyslipidemia, and cardiovascular disease at the end of the follow-up were higher for the individuals in the TC group who died during the follow-up period of the current study than among those in the non-TC group who died. These differences between the groups at study closure were greater than those recorded at baseline.

The treatment of TC may affect the mortality risk in a number of ways. The majority of the Israeli TC survivors were treated according to a standard of care consisting of thyroidectomy, radioactive ablation, and thyroid hormone suppression treatment. Several studies have shown a greater risk of second primary cancer among TC survivors treated with radioactive ablation than among those who did not undergo such treatment. ${ }^{17,18}$ This increased risk was shown to also prevail among low-risk TC survivors ${ }^{22}$ and only when the cumulative radioactive iodine dose was $\geq 37.0 \mathrm{GBq} .^{23}$ The mortality risk was also higher for the $5-15 \%$ of TC survivors who become refractory to radioactive iodine therapy. ${ }^{24,25}$

Thyroid hormone suppression is a component of TC treatment, both for those who respond and for those who are refractory to radioactive iodine therapy. Associations have been reported among thyroid hormone suppression treatment and atrial fibrillation, ${ }^{26}$ impaired small and large artery elasticity, ${ }^{27}$ increased left ventricular mass, ${ }^{27}$ abnormalities of heart morphology related to impaired exercise performance, ${ }^{28} \mathrm{a}$ prothrombotic condition, ${ }^{29}$ and myocardial strain. ${ }^{30}$ In the absence of data on thyroid hormone treatment, we do not know the degree to which subclinical hyperthyroidism was achieved in the TC survivors, or the proportion of individuals in the TC group that may have had endogenous subclinical hyperthyroidism. However, subclinical hyperthyroidism not in the setting of TC has been shown to be associated with atrial fibrillation ${ }^{31,32}$ worse physical capacity, ${ }^{33}$ increased risk of heart failure, and cardiovascular morbidity. ${ }^{32,34}$ Moreover, endogenous subclinical hyperthyroidism was associated with increased risks of total and cardiovascular mortality in a pooled analysis from 10 cohorts of individuals not treated with thyroxine. ${ }^{31} \mathrm{~A}$ Danish population-based study found increased heart failure and increased cardiovascular and all-cause mortality among patients with subclinical hyperthyroidism compared to euthyroid individuals. ${ }^{35}$ In contrast with these reports, a recently published small study with up to a 9-year follow-up showed no impairment in cardiac function and structure among individuals who received thyroid hormone suppression treatment. ${ }^{36}$ However, the patients' thyroid-stimulating hormone (TSH) levels in that study were $<0.1 \mathrm{mU} / \mathrm{L}$ in the intermediate-risk-of-recurrence group and $<0.3 \mathrm{mU} / \mathrm{L}$ in the lower-riskof-recurrence group, which is higher than the recommendations for TSH suppression. Having no data on TSH levels during the follow-up in our cohort, we were unable to compile the effects of treatment on mortality.

Health-related quality of life (HRQoL) is an additional factor that may affect health and long-term mortality in cancer survivors. A recent publication reported that 14-17 years after diagnosis, almost half of DTC survivors who filled in a HRQoL questionnaire expressed anxiety about disease recurrence, and that this negatively impacted their HRQoL. ${ }^{37}$ Poor HRQoL has been found to be related to all-cause mortality in various populations. ${ }^{38,39}$ 
Stage at diagnosis ${ }^{2,15}$ and genetic variance ${ }^{40}$ have been shown to affect mortality. The current study did not distinguish between types of TC. DTC, which comprised the vast majority of TCs in our population, confers considerably better prognosis than do the less common types of TC. ${ }^{1}$

The strengths of this study are the long-term follow-up findings of a large population-based cohort, which are based on the computerized data file of the largest healthcare fund in Israel (covering around $52.3 \%$ of the total Israeli population). They take into account baseline pathological conditions and those diagnosed during the follow-up period of the study (including dyslipidemia, hypertension, diabetes mellitus, cardiovascular and cerebrovascular diseases, and new malignancies). A significant limitation of this study is the lack of data on the cause of death, as well as on other variables, such as the histological variant of the TC, the stage of the TC, the doses of radioactive iodine treatment, and the TSH levels during the follow-up period.

In summary, the finding of a higher all-cause mortality risk in TC survivors compared to the general population, despite the excellent prognosis and the decreasing fatality rates for TC, is of concern. In the current study, a higher prevalence of hypertension, dyslipidemia, and cardiovascular disease at the end of the follow-up period was associated with mortality among the group of Israeli TC survivors. Moreover, we found a direct association between the number of cardiovascular risk factors at the end of the follow-up and the mortality risk among TC survivors. As such, our findings suggest that cardiovascular risk factors may predict higher mortality in TC survivors compared to non-TC individuals. We therefore recommend a high level of awareness of cardiovascular risk factors, their follow-up, and their treatment among TC survivors, with the aim of reducing the risk of mortality among them.

\section{Abbreviations}

$\mathrm{TC}=$ thyroid cancer; $\mathrm{HR}$ = hazard ratio; $\mathrm{Cl}=$ confidence interval; SEER = United State Surveillance, Epidemiology, and End Results; DTC = differentiated thyroid cancer; CHS = Clalit Health Services; LDL = Iow density lipoprotein; ICD = International Statistical Classification of Diseases and Related Health Problems; TNM = tumor-node-metastasis; $\mathrm{TSH}$ = thyroid-stimulating hormone; $\mathrm{HRQ}$ oL = health-related quality of life.

\section{Declarations}

\section{Ethics approval and consent to participate:}

The Helsinki Medical Ethics Committee of the Clalit Health Services provided approval to conduct this study (approval \# 0040-15-COM) and waived signed informed consent since the study was based on existing databases.

\section{Consent for publication:}


Not applicable.

\section{Availability of data and materials:}

The data that support the findings of this study are available from database of Clalit Health Services, but restrictions apply to the availability of these data, which were used under license for the current study, and so are not publicly available. Data are however available from the authors upon reasonable request and with permission of Clalit Health Services.

\section{Competing interests:}

The authors declare that they have no competing interests.

\section{Funding:}

None.

\section{Authors' contributions:}

Conceptualization: E.I. Design: I.E., L.K.B., M.B., and J.M. Acquisition of data: E.I., L.K.B., M.B., Y.S., I.Y., N.N.C.N, D.M.F, N.S., and J.M. Statistical analysis and interpretation: I.E., L.K.B., M.B., Y.S., and J.M. Manuscript writing: E.I., L.K.B., M.B., Y.S., N.S., and J.M. Approval of the final text: All authors have read and approved the manuscript.

\section{Acknowledgments:}

We thank Esther Eshkol, MA, the institutional medical and scientific copyeditor, for editorial assistance.

\section{References}

1. Davies L, Welch HG. Current thyroid cancer trends in the United States. JAMA Otolaryngol Head Neck Surg. 2014;140:317-22.

2. Lim H, Devesa SS, Sosa JA, Check D, Kitahara CM. Trends in thyroid cancer incidence and mortality in the United States,1974-2013. JAMA. 2017;317:1338-48.

3. La Vecchia C, Malvezzi M, Bosetti C, Garavello W, Bertuccio P, Levi F, et al. Thyroid cancer mortality and incidence: a global overview. Int J Cancer. 2015;136:2187-95.

4. Keinan-Boker L, Silverman BG. Trends of thyroid cancer in Israel: 1980-2012. Rambam Maimonides Med J. 2016;7(10).

5. Oberman B, Khaku A, Camacho F, Goldenberg D. Relationship between obesity, diabetes and the risk of thyroid cancer. Am J Otolaryngol. 2015;36:535-41. 
6. Gazdag A, Nagy EV, Erdei A, Bodor M, Berta E, Szabó Z, et al. Aortic stiffness and left ventricular function in patients with differentiated thyroid cancer. J Endocrinol Invest. 2015;38:133-42.

7. Taillard V, Sardinoux M, Oudot C, Fesler P, Rugale C, Raingeard I, et al. Early detection of isolated left ventricular diastolic dysfunction in high-risk differentiated thyroid carcinomapatients on TSHsuppressive therapy. Clin Endocrinol (Oxf). 2011;75:709-14.

8. Yang L, Shen W, Sakamoto N. Population based study evaluating and predicting the probability of death resulting from thyroid cancer and other causes among patients with thyroid cancer. $\mathrm{J}$ Clin Oncol. 2013;31:468-74.

9. Izkhakov E, Meyerovitch J, Barchana M, Shacham Y, Stern N, Keinan-Boker L. Long-term cardiovascular and cerebrovascular morbidity in Israeli thyroid cancer survivors. Endocr Connect. 2019;8(4):398-06.

10. Klein Hesselink EN, Klein Hesselink MS, de Bock GH, Gansevoort RT, Bakker SJ, Vredeveld EJ, et al. Long-term cardiovascular mortality in patients with differentiated thyroid carcinoma: an observational study. J Clin Oncol. 2013;31:4046-53.

11. Ahn HS, Kim HJ, Welch HG. Korea's thyroid-cancer "epidemic"-screening and overdiagnosis. N Engl J Med. 2014;371:1765-67.

12. Konturek A, Barczyński M, Stopa M, Nowak W. Trends in prevalence of thyroid cancer over three decades: a retrospective cohort study of 17,526 surgical patients. World J Surg. 2016;40:538-44.

13. Nixon IJ, Wang LY, Migliacci JC, Eskander A, Campbell MJ, Aniss A, et al. An international multiinstitutional validation of age 55 years as a cutoff for risk stratification in the AJCC/UICC Staging System for Well-Differentiated Thyroid Cancer. Thyroid. 2016;26:373-80.

14. Ganly I, Nixon IJ, Wang LY, Palmer FL, Migliacci JC, Aniss A, et al. Survival from differentiated thyroid cancer: what has age got to do with it? Thyroid. 2015;25:1106-14.

15. Verburg FA, Mäder U, Tanase K, Thies ED, DiessI S, Buck AK, et al. Life expectancy is reduced in differentiated thyroid cancer patients $\geq 45$ years old with extensive local tumor invasion, lateral lymph node, or distant metastases at diagnosis and normal in all other DTC patients. $\mathrm{J}$ Clin Endocrinol Metab. 2013;98:172-80.

16. Izkhakov E, Barchana M, Liphshiz I, Silverman BG, Stern N, Keinan-Boker L. Trends of second primary malignancy in patients with thyroid cancer: a population-based cohort study in Israel. Thyroid. 2017;27(6):793-01.

17. Brown AP, Chen J, Hitchcock YJ, Szabo A, Shrieve DC. Toward JD. The risk of second primary malignancies up to three decades after the treatment of differentiated thyroid cancer. J Clin Endocrinol Metab. 2008;93:504-15.

18. Liou MJ, Tsang NM, Hsueh C, Chao TC, Lin JD. Therapeutic outcome of second primary malignancies in patients with well-differentiated thyroid cancer. Int J Endocrinol. 2016;9570171.

19. Kuijpens JL, Janssen-Heijnen ML, Lemmens VE, Haak HR, Heijckmann AC, Coebergh JW. Comorbidity in newly diagnosed thyroid cancer patients: a population-based study on prevalence and the impact on treatment and survival. Clin Endocrinol (Oxf). 2006;64:450-55. 
20. Dankner R, Boffetta P, Balicer RD, Keinan Boker L, Sadeh M, Berlin A, et al. Time-Dependent Risk of Cancer After a Diabetes Diagnosis in a Cohort of 2.3 Million Adults. Am J Epidemiol. 2016;183:1098-06.

21. Chen ST, Hsueh C, Chiou WK, Lin JD. Disease-specific mortality and secondary primary cancer in well-differentiated thyroid cancer with type 2 diabetes mellitus. PLoS One. 2013;8:e55179.

22. Iyer NG, Morris LG, Tuttle RM, Shaha AR, Ganly I. Rising incidence of second cancers in patients with low-risk (T1N0) thyroid cancer who receive radioactive iodine therapy. Cancer. 2011;117:4439-46.

23. Khang AR, Cho SW, Choi HS, Ahn HY, Yoo WS, Kim KW, et al. The risk of second primary malignancy is increased in differentiated thyroid cancer patients with a cumulative (131) I dose over $37 \mathrm{GBq}$. Clin Endocrinol (Oxf). 2015;83:117-23.

24. Sciuto R, Romano L, Rea S, Marandino F, Sperduti I, Maini C. Natural history and clinical outcome of differentiated thyroid carcinoma: a retrospective analysis of 1503 patients treated at a single institution. Ann Oncol. 2009;20:1728-35.

25. Durante C, Haddy N, Baudin E, Leboulleux S, Hartl D, Travagli J, et al. Long-term outcome of 444 patients with distant metastases from papillary and follicular thyroid carcinoma: benefits and limits of radioiodine therapy. J Clin Endocrinol Metab. 2006;91:2892-99.

26. Abonowara A, Quraishi A, Sapp JL, Alqambar MH, Saric A, O'Connell CM, et al. Prevalence of atrial fibrillation in patients taking TSH suppression therapy for management of thyroid cancer. Clin Invest Med. 2012;35:E152-E56.

27. Shargorodsky M, Serov S, Gavish D, Leibovitz E, Harpaz D, Zimlichman R. Long-term thyrotropinsuppressive therapy with levothyroxine impairs small and large artery elasticity and increases left ventricular mass in patients with thyroid carcinoma. Thyroid. 2006;16:381-86.

28. Mercuro G, Panzuto MG, Bina A, Leo M, Cabula R, Petrini L, et al. Cardiac function, physical exercise capacity, and quality of life during long-term thyrotropin-suppressive therapy with levothyroxine: effect of individual.dose.tailoring. J Clin Endocrinol Metab. 2000;85:159-64.

29. Horne MK 3rd, Singh KK, Rosenfeld KG, Wesley R, Skarulis MC, Merryman PK, et al. Is thyroid hormone suppression therapy prothrombotic? J Clin Endocrinol Metab. 2004;89:4469-73.

30. Abdulrahman RM, Delgado V, Hoftijzer HC, Ng AC, Ewe SH, Marsan NA, et al. Both exogenous subclinical hyperthyroidism and short-term overt hypothyroidism affect myocardial strain in patients with differentiated thyroid carcinoma. Thyroid. 2011;21:471-76.

31. Collet TH, Gussekloo Bauer DC, den Elzen WP, Cappola AR, Balmer P, lervasi G, et al. Subclinical hyperthyroidism and the risk of coronary heart disease and mortality. Arch Intern Med. 2012;172:799-809.

32. Gencer B, Collet TH, Virgini V, Auer R, Rodondi N. Subclinical thyroid dysfunction and cardiovascular outcomes among prospective cohort studies. Endocr Metab Immune Disord Drug Targets. 2013;13:4-12.

33. Kaminski G, Dziuk M, Szczepanek-Parulska E, Zybek-Kocik A, Ruchala M. Electrocardiographic and scintigraphic evaluation of patients with subclinical hyperthyroidism during workout. Endocrine. 
2016;53:512-19.

34. Vadiveloo T, Donnan PT, Cochrane L, Leese GP. The Thyroid Epidemiology, Audit, and Research Study (TEARS): morbidity in patients with endogenous suclinical hyperthyroidism. J Clin Endocrinol Metab. 2011;96:1344-51.

35. Selmer C, Olesen JB, Hansen ML, von Kappelgaard LM, Madsen JC, Hansen PR, et al. Subclinical and overt thyroid dysfunction and risk of all-cause mortality and cardiovascular events: a large population study. J Clin Endocrinol Metab. 2014;99:2372-82.

36. Hong KS, Son JW, Ryu OH, Choi MG, Hong JY, Lee SJ. Cardiac effects of thyrotropin oversuppression with levothyroxine in young women with differentiated thyroid Cancer. Int $\mathrm{J}$ Endocrinol. 2016;9846790.

37. Hedman C, Djärv T, Strang P, Lundgren Cl. Determinants of long-term quality of of life in patients with differentiated thyroid carcinoma - a population-based.cohort.study in Sweden. Acta Oncol. 2016;55:365-69.

38. Myint PK, Luben RN, Surtees PG, Wainwright NW, Welch AA, Bingham SA, et al. Self-reported mental health-related quality of life and mortality in men and women in the European Prospective Investigation into Cancer (EPIC-Norfolk): a prospective population study. Psychosom Med. 2007;69:410-14.

39. Xie G, Laskowitz DT, Turner EL, Egger JR, Shi P, Ren F, et al. Baseline health-related quality of life and 10-year all-cause mortality among 1739 Chinese adults. PLoS One. 2014;9:e101527.

40. Świerniak M, Wójcicka A, Czetwertyńska M, Długosińska J, Stachlewska E, Gierlikowski W, et al. Association between GWAS-derived rs 966423 genetic variant and overall mortality in patients with differentiated thyroid cancer. Clin Cancer Res. 2016;22:1111-19.

\section{Figures}




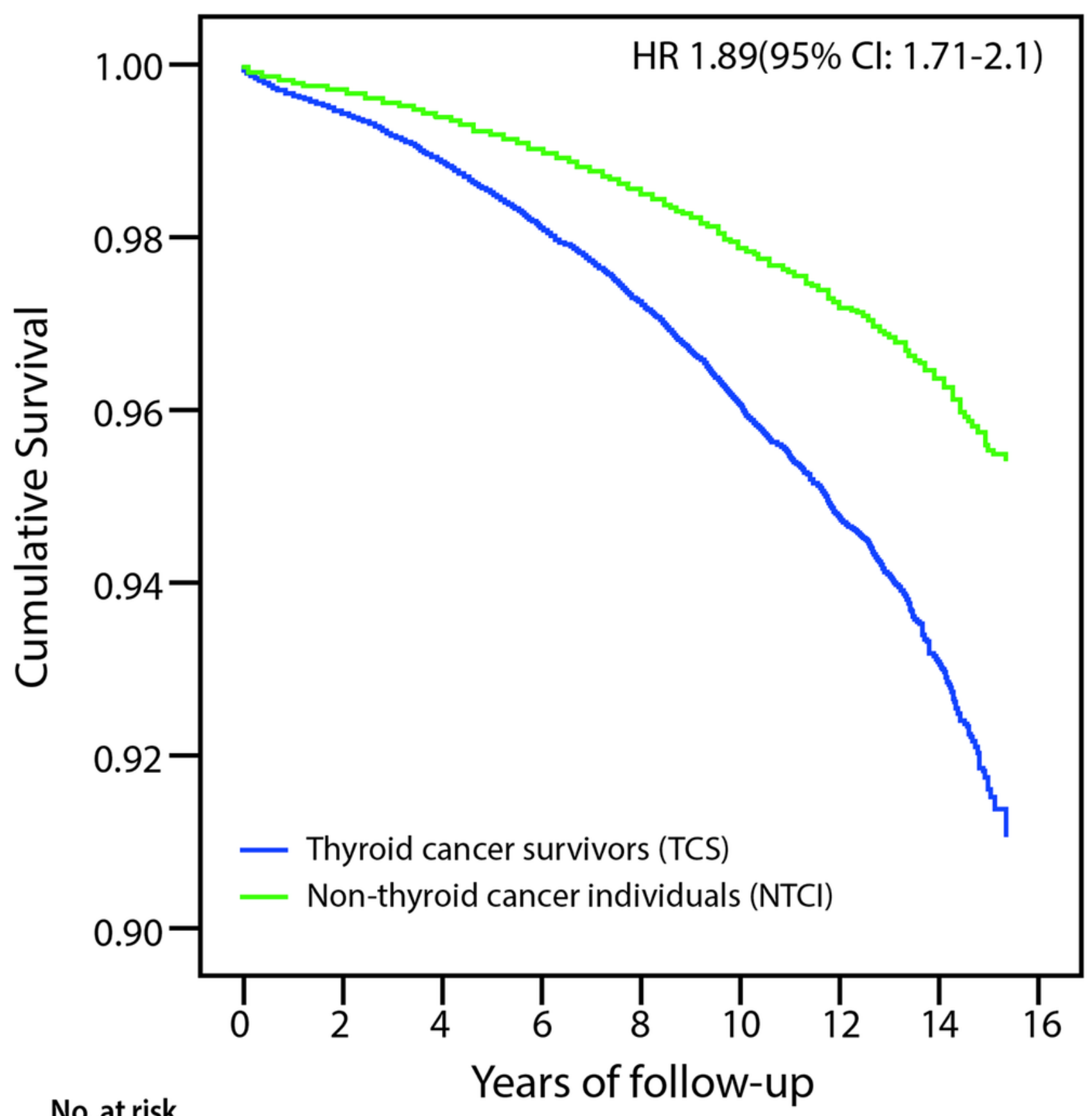

No. at risk

$\begin{array}{lllllllll}\text { TCS } & 5677 & 5303 & 4310 & 3336 & 2460 & 1751 & 1141 & 487\end{array}$

NTCl $\quad 23962 \quad 22978 \quad 18736 \quad 14579 \quad 10830 \quad 7671 \quad 5024 \quad 2228$

\section{Figure 1}

Kaplan-Meier survival curves for the thyroid cancer survivors $(n=5,677)$ and non-thyroid cancer individuals $(n=23,962)$. The survival curve is steeper for the thyroid cancer (blue) than for the non-cancer (green) groups. The data were adjusted for age, sex, cerebrovascular and cardiovascular disease, hypertension, diabetes mellitus, dyslipidemia, and current smoking. 